\title{
Notas sobre el teletrabajo, la atención psiquiátrica y los cambios comunicacionales en pandemia
}

Notes on telework, psychiatric care and changes in communication during pandemic

\section{Daniel Matusevich', Martín Nemirovsky²}

\section{Resumen}

El COVID-I 9 ha acelerado las transformaciones del teletrabajo, generando condiciones de grandes oportunidades y terribles amenazas. La brecha digital profundiza las inequidades y la explotación, donde los países más desprotegidos y las poblaciones más vulnerables están más cerca del abismo. Los cambios digitales han formateado nuevos modos asistenciales, que se encuentran en permanente cambio y presentan nuevos desafíos para encontrar sus alcances y sus límites.

Palabras clave: Redes Sociales - COVID-19 - Teletrabajo - Brecha digital.

\section{Abstract}

COVID-I 9 has accelerated the transformations of teleworking, generating conditions of great opportunities and terrible threats. The digital divide deepens inequities and exploitation, where the most unprotected countries and the most vulnerable populations are closer to the abyss Digital changes have formatted new modes of care, which are constantly changing and present new challenges to find their scope and limits.

Keywords: Social Networks - COVID-19 - Teleworking - Digital divide. 
Me temo que la época de los libros capaces de cambiar el mundo ha quedado atrás. Ahora son las apps y las redes sociales las que tienen ese poder transformador.

\section{Jorge Carrión.}

\section{Introducción}

La pandemia que estamos atravesando ha definido cambios radicales en una gran cantidad de hábitos y costumbres, lo que ha determinado profundas modificaciones en nuestra manera de vivir. Cuáles de estos son temporales y cuáles han llegado para quedarse será algo que iremos viendo con el devenir del tiempo.

Una de las transformaciones más significativas y complejas se puede observar en el campo laboral, con el advenimiento del teletrabajo o trabajo virtual; si bien esta modalidad ya se había expresado tímidamente en algunas sociedades y ámbitos, es en tiempos del virus SARS-CoV-2 donde floreció para alcanzar un desarrollo nunca antes imaginado.

En un artículo recientemente publicado, Laura Ripani explica la evolución del concepto: al principio se hablaba de "oficina en el hogar", ya que el hecho de poder tener tecnología como computadoras e Internet en casa abrió la oportunidad de trabajar fuera de la empresa; luego se acuñó el concepto de "oficina móvil”, ya que los teléfonos celulares, laptops y tabletas permitieron que el teletrabajo no tenga que ser realizado exclusivamente desde la casa, sino desde cualquier lugar adonde haya una conexión a Internet o a una red de datos; la última etapa de esta evolución es la "oficina virtual", que expande el concepto anterior con la aparición de los teléfonos inteligentes y la capacidad de tener información en la nube: todo lo que necesitamos para teletrabajar ahora entra en la palma de la mano (Ripani, 2020).

\section{Teletrabajo y cambios en la comunica- ción}

El análisis de los datos nos dice que el porcentaje de trabajos que tiene potencial para realizarse desde el hogar se encuentra entre un $27 \%$ y un $29 \%$ de los trabajos totales (Ver Figura 1).

El teletrabajo es un concepto con cada vez más aceptación en América Latina. Antes de la pandemia de coronavirus, Brasil era el país con más empleados trabajando desde sus casas, con 12 millones de teletrabajadores, seguido por México (2,6 millones), Argentina (2 millones) y Chile (500 mil).
Figura I. La evolución del teletrabajo

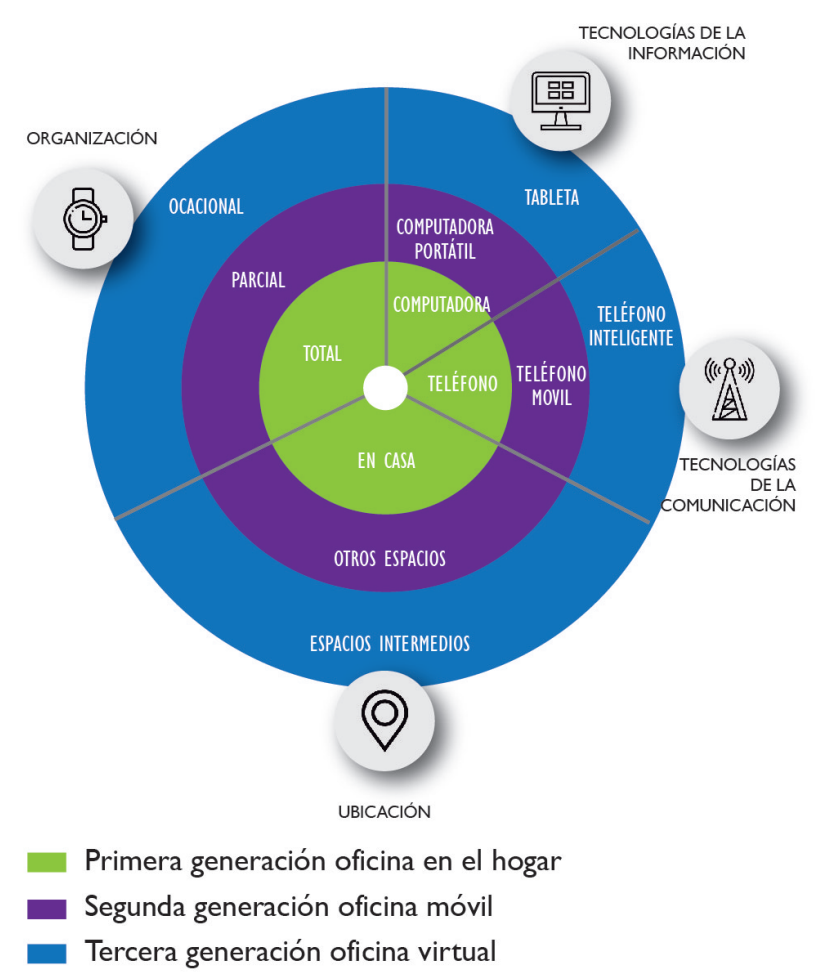

Fuente: Messenger y Gschwind (2016)

Ahora bien, teletrabajar en nuestro continente pone en evidencia un choque entre dos mundos: el de aquellos que gracias a la tecnología pueden hacerlo desde donde sea y el de la inmensa cantidad de personas que quedan afuera del sistema, debido a la extrema desigualdad estructural que existe en el mundo y que define a la mayor parte de las sociedades. Las transformaciones del capitalismo, la globalización, el derrumbe de la Unión Soviética, la crisis de 2008 y el terrorismo sacudieron a las sociedades industriales, nacionales y democráticas: los trabajadores poco calificados están sometidos a la competencia de los países emergentes, convertidos en las fábricas del planeta.

Algunas de las ventajas de esta modalidad radican especialmente en la flexibilidad para aquellas personas que tienen compromisos familiares y personales (por ejemplo, cuidado de hijos o de adultos mayores) que les impiden su labor fuera del hogar en horario completo. Por otro lado, permite una mayor accesibilidad, ayudando a derribar las barreras estructurales que enfrentan las personas con discapacidades para acceder a un empleo, y también vale la pena considerar que la mirada ecológica pone el eje cada vez más en la disminución de la contaminación ambiental al minimizar los desplazamientos. 
Entre las desventajas, el trabajo virtual hace que cada vez sea más difícil definir de qué hora a qué hora trabajamos, pudiendo tener efectos negativos tanto en nuestra salud mental como en la física. Esto genera un desequilibrio entre la vida personal y la vida profesional al diluir las fronteras entre estos dos ámbitos; en especial una carga inusitada se abatió sobre aquellas mujeres que además de ejercer la función de cuidadoras familiares desempeñan cualquier otro tipo de tareas, llegando exhaustas al cabo de casi dos años de pandemia.

No solamente la intensidad de los estímulos virtuales nos asalta en los horarios en los cuales trabajamos sino también en otras circunstancias y lugares en los cuales chequeamos o producimos información (auto, cine, baño, cena familiar o con amigos, etc.), generándose de esta manera un continuum infinito de comunicación que plantea un enorme desafío a la serenidad y a la capacidad de reflexión.

Quizás ha sido Byung Chul Han quien más agudizó la crítica a las contradicciones de la oficina virtual; ya en The burnout society (traducido entre nosotros como La sociedad del cansancio), publicado en el año 2012, planteó claramente que: “....en la sociedad neoliberal del rendimiento se lleva a cabo una explotación sin autoridad. El sujeto forzado a rendir, a explotarse a sí mismo, es a la vez amo y esclavo. Por así decirlo, cada uno lleva consigo su propio campo de trabajos forzados. Lo peculiar de este campo de trabajos forzados es que uno es al mismo tiempo prisionero y vigilante, víctima y criminal. En eso se diferencia del sujeto obediente de la sociedad disciplinaria, que Foucault describe en su libro Vigilar y castigar. Pero Foucault no se dio cuenta del surgimiento de la sociedad neoliberal del rendimiento, en la que nos explotamos voluntariamente" (Chul Han, 2012).

Es decir, la vida vivida como una carrera de obstáculos que nunca termina y que, como premios principales, tienen al stent y a la depresión. Leer al filósofo nacido en Seúl es una experiencia muy recomendable, sus escritos combinan con maestría profundidad, ironía, belleza y un leve aire Zen que sobrevuela todo y nos ayuda a comprender unos tiempos únicos. Por ejemplo, en su último libro No-cosas plantea que vivimos en un mundo vacío de cosas y lleno de información, en el cual la digitalización desmaterializa y "descorporiza", imaginando a la mujer o al varón de nuestros tiempos como un cazador de información, ciego ante las cosas silenciosas y discretas, que son las que nos anclan en el ser y no en el tener (Chul Han, 2021).

Al decir de Jorge Carrión, un fenómeno biológico, el virus, nos está hundiendo en la virtualidad; si al ritmo de hace dos años la transición digital se hubiera completado en treinta años, tras la pandemia ese plazo se verá reducido de manera drástica. Se ha producido la caída del dogma de infalibilidad occidental y ha avanzado una patología construida por la universalización y por los desplazamientos (Carrión, 2020).

\section{La atención en salud mental}

En medio de estos cambios y contradicciones el campo de la Salud Mental es quizás uno de los más trasformados por el advenimiento de la virtualidad en nuestras vidas: psicoterapias, reuniones de equipo, supervisiones, clases y seminarios migraron a ese formato con una rapidez más cercana a la supervivencia que a la reflexión.

Desde el inicio de la pandemia nos encontramos habitando un nuevo mundo con reglas propias, algunas implícitas y otras explicitas, que condicionan nuestra práctica, prefigurado por Alessandro Baricco en el imprescindible The Game; así, podemos señalar: pacientes que no hemos conocido en su versión de carne y hueso a lo largo de meses, o que no conoceremos nunca (en persona), consultas en regiones remotas a nuestra ubicación pero sin una clara legislación que regule esa práctica o las implicancias del ejercicio docente en modo virtual frente a cámaras apagadas y micrófonos silenciados, etc., etc. (Baricco, 2019).

Las terapias mediatizadas a través de las plataformas Zoom, Skype, WhatsApp o directamente el teléfono (poniendo el eje simplemente en el lenguaje) han permitido que millones de personas continúen llevando adelante sus procesos terapéuticos, que otras directamente los inicien y que la "psico comunicación" fluya, de una forma u otra; aunque en este punto también podemos acordar en que las redes se transformaron en actores principales a la hora de ayudar a disminuir el aislamiento, la distancia, la soledad y en permitir llevar adelante nuevos modelos de psicoterapias.

En muchos casos aquellas y aquellos que tuvieron la posibilidad de despedirse de sus próximos murientes, pudieron hacerlo al menos de manera virtual, iniciando duelos inéditos para nuestra sociedad. Por supuesto que vale la pena preguntarnos qué clase de despedida es aquella intermediada por un teléfono celular; es una pregunta que nos iremos formulando repetidamente en los años por venir, pero, mientras tanto, al menos muchas y muchos de nosotros pudieron decir su adiós y eso no es poca cosa.

¿Cómo se terminarán de configurar estos nuevos vínculos tecnológicos que están definiendo un cambio profundo en el encuadre que enmarcan las relaciones 
terapéuticas? Un ejercicio vintage acorde a estos tiempos que nos tocan vivir sería revisar el clásico artículo de José Bleger acerca del encuadre terapéutico (Bleger, 1967), con el que aquellos que superamos la barrera de los cincuenta nos formamos, e imaginar como podría ser reescrito hoy en tiempos en los que la esfera íntima se ha estrechado y aspectos como la estética, el consumo y las aficiones personales han tomado el control de las relaciones personales y profesionales.

¿Dónde empieza y termina el accionar de un profesional de la salud con sus pacientes? ¿Es de presencia las 24 horas, los 365 días al año? Tal vez una de las cuestiones más complejas a analizar tenga que ver con la redefinición de los ámbitos, público y privado, tanto para los terapeutas como para los pacientes. Nuevas situaciones llegaron (quizás para quedarse): la foto de WhatsApp, Instagram, Facebook, googlear al otro como parte del proceso de conocerlo, la transferencia de honorarios, etc. Estamos asistiendo a cambios definitivos en el concepto de intimidad y a la desaparición de la neutralidad terapéutica; en palabras de Sabater Fernández: “...el ciudadano, reconvertido en internauta, adquiere nuevos hábitos de privacidad al compartir, libremente o no, sus datos con la compañía y con su red de contactos, en la que figuran personas que no son conocidas de forma personal directa. La identidad pública se ve ampliada en forma de una identidad digital que comprende el historial de navegación; los datos privados aportados en redes sociales, en comunidades virtuales, en el registro de nuestros correos electrónicos; nuestros hobbies y aficiones expuestos en el muro o en forma de tweets; nuestras fotos privadas en fotolog y en los perfiles de las redes sociales, e incluso, los sentimientos más profundos se permean en forma de blogs íntimos" (Sabater Fernández, 2014).

Los pacientes pueden comunicarse a través de las tecnologías sin restricciones de horarios, decir lo que les parece, pedir recetas sistemáticamente, iniciar conversaciones fuera de los contratos preestablecidos, comentar distintas variantes de estar en riesgo; estas son solo algunas de las variadas formas en que los cambios producidos por la pandemia nos interpelan y redefinen nuestro lugar profesional.

\section{Conclusiones}

Vivimos en una sociedad caracterizada por las despedidas, el virus simplemente acentuó la transitoriedad de nuestros vínculos humanos y materiales, pero ahora que pareciera que lo peor ya transcurrió ( ¿ya transcurrió?) es necesario que analicemos nuestros lazos (terapéuticos y de los otros) para pensar qué vida y en qué mundo queremos vivir, si imaginamos un futuro exclusivamente digital o si habrá lugar para otro tipo de comunicaciones. El panorama planteado por Umberto Eco en 1964 en su clásico Apocalípticos e integrados se ha complejizado notablemente, los filósofos y los intelectuales navegan en la Web (Hasta Chul Han lo hace) y formulan sus críticas y comentarios desde adentro, las viejas oposiciones no son suficientes para comprender una realidad más cercana a los escenarios post apocalípticos descriptos por James Ballard que a cualquier mundo imaginado por cientistas sociales (Eco, 2012).

El doctor Charles Ransom, arquetípico protagonista Ballardiano de La Sequía, reflexiona en soledad acerca de que el ocaso planetario traerá mucho más que la cancelación de la vida; a la extinción de la especie la antecederá una extinción del sentido, morirán con el hombre su cultura, su historia y su misterio (Ballard, 1979).

Este y otros análisis se desprenden de todo lo acontecido, generando un campo de debate y reflexión que recién está en sus comienzos; la psiquiatría, la psicología y todos los actores del universo Salud Mental nos enfrentamos al reto inédito de tener que trabajar, pensar y dar sentido en un mundo en el cual, al decir de Jorge Carrion, el nuevo realismo es la ciencia ficción (Carrión, 2020).

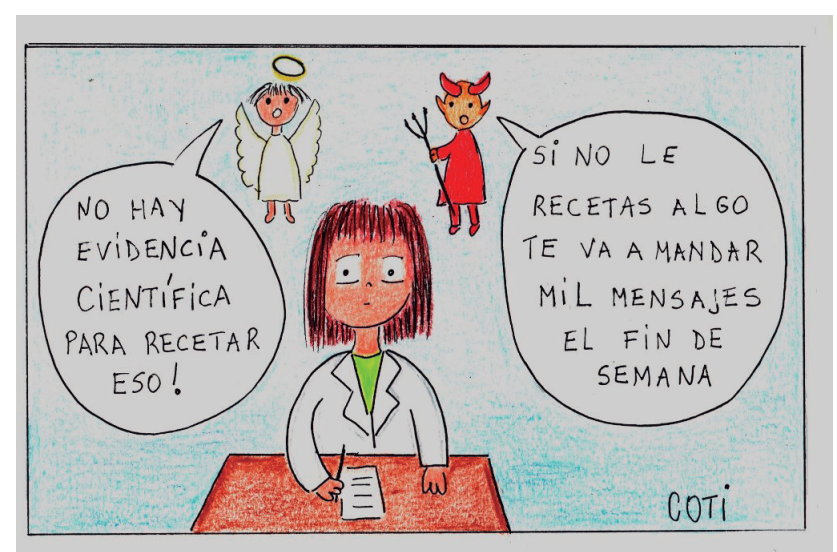

(Funes, 202I)

Conflicto de intereses: los autores, que forman parte del equipo de la revista, declaran no tener conflictos de intereses en relación con el contenido del presente artículo. Agradecimiento: los autores agradecen muy especialmente a Coty Funes y sus increíbles @gajosdeloficio. 


\section{Referencias bibliográficas}

Ballard J. (1979). La sequía. Minotauro.

Baricco, A. (2019). The game. Anagrama.

Bleger, J. (1967). Psicoanálisis del encuadre psicoanalítico. En: J. Bleger Simbiosis y Ambigüedad (pp. 241-258). Editorial Paidós.

Carrión, J. (2020). Lo viral. Galaxia Gutenberg.

Chul Han, B. (2012). La sociedad del cansancio. Herder.

Chul Han, B. (2021). No-cosas. Taurus.
Eco, U. (2012). Apocalípticos e integrados. Debolsillo.

Funes, C. (2021). Pequeños gajos del oficio. Del Hospital Ediciones.

Ripani, L. (2020, 24 de marzo). Coronavirus: un experimento de tele trabajo a escala mundial. https://blogs.iadb.org/trabajo/es/coronavirus-un-experimento-de-teletrabajo-a-escala-mundial/

Sabater Fernández, C. (2014). La vida privada en la sociedad digital. La exposición pública de los jóvenes en internet. Aposta Revista de Ciencias Sociales, 61, 1-32. 